\title{
Presença da Psicologia Histórica no Brasil
}

\author{
Maria Fernanda Costa Waeny \\ Psicológa
}

\begin{abstract}
Resumo
Costuma-se afirmar que Henri Berr foi o primeiro autor que usou o termo psicologia histórica, em 1899. Desde então, citações a ela têm sido recorrentes na literatura acadêmica mundial. No Brasil, porém, a primeira menção até agora localizada data de 1877. Entre esta citação e o reaparecimento do termo, em 1978, surgiram vários títulos estrangeiros - alguns dos quais traduzidos para o português. A partir da década de 1980, psicologia histórica foi tema de artigos e figurou como disciplina em cursos de psicologia, em nível de graduação e pós, tema de dissertações e de apresentações em congressos. O objetivo do artigo é traçar os primórdios da psicologia histórica tal como comumente aceita e apresentar dados sobre sua história no Brasil, mencionando alguns de seus autores e pesquisadores.
\end{abstract}

Palavras-chave: Ignace Meyerson; psicologia histórica; história da psicologia.

\begin{abstract}
Presence of Historical Psychology in Brazil. It is often said that Henri Berr was the first author who used the term historical psychology, in 1899. Citations have been referred to it in the worldwide academic literature since then. However, in Brazil, the first mention so far found out is from 1877. Between this citation and the reappearance of the term, in 1978, several foreign titles appeared - some of then translated into Portuguese. Historical psychology was the subject of articles from the 1980s and figured out as a discipline in psychology courses, in undergraduate and postgraduate levels, subject of dissertations and lectures in congresses. The aim of the paper is to trace the beginning of historical psychology as commonly accepted, and to present data about its history in Brazil, mentioning some of its authors and researchers.
\end{abstract}

Keywords: Ignace Meyerson; historical psychology; history of psychology.

\section{Resumen}

Presencia de la Psicología Histórica en Brasil. Se acostumbra a decir que Henri Berr fue el primer autor que utilizó el término psicología histórica en 1899. Desde entonces, las citaciones a la psicología histórica han sido recurrentes en la literatura académica mundial. En Brasil, sin embargo, la primera mención hasta ahora averiguada es de 1877. Entre esta cita y la reaparición del término, en 1978, hubo varios títulos extranjeros - algunos de los cuales traducidos al português. Desde la década de 1980, la psicología histórica fue objeto de artículos y figuró como disciplina en los cursos de psicología, de grado y postgrado, disertaciones y conferencias en los congresos. El objetivo de este artículo es rastrear las orígenes de la psicología histórica como datos comúnmente aceptados y presentes en su historia en Brasil, citando algunos de los autores y investigadores.

Palabras clave: Ignace Meyerson; psicología histórica; historia de la psicología.

$\mathrm{P}$ sicologia histórica é um termo geralmente associado a historiadores dos Annales; Burke (1990), por exemplo, o vincula a Lucien Febvre, Marc Bloch, Robert Mandrou, além de breves menções a Henri Berr, Henri Bremond, Ignace Meyerson, Jean Delumeau e Jean-Pierre Vernant. Burke (1990) afirma que o termo foi usado por Berr em 1900, com o objetivo de produzir uma psicologia histórica "através de uma cooperação interdisciplinar" (p. 22). Berr, no entanto, já havia mencionado o termo na tese de 1899, L'Avenir de la philosophie, na qual afirmou que o surgimento de diferentes psicologias (ele cita psicologia da humanidade, dos povos e biográfica) e outros textos com o mesmo teor anunciam "uma psicologia histórica que se elabora, sem ter encontrado sua forma definitiva" (citado por Chalus, 1961, p. 9).

Psicologia histórica também aparece associada aos termos mentalidades, antropologia histórica, psicohistória (ou psicohistória); os autores aludem ora a uma disputa, ora sobreposição, ora oposição entre essas denominações. Disto resulta, em parte, a alternância e a imprecisão na delimitação e definição desses termos. Para Burke (1990), por exemplo, na "disputa com o termo 'mentalidades', [psicologia histórica] foi o perdedor" ( $p$ 
132); para Dosse (1994) o conceito de mentalidade "permitiu a constituição de uma psico-história" (p. 84). Dosse inclui Vernant na escola francesa de antropologia histórica (p. 89); Burke (1990) estranha que o livro de Vernant, Mito e pensamento entre os gregos. Estudos de psicologia histórica, "presta homenagem não a Febvre, mas ao psicólogo I. Meyerson” (p. 114).

No Brasil se mantém essa mesma dificuldade em relação ao limite dos termos. Para Penna (1987), por exemplo, psicologia histórica e história das mentalidades se equivalem, e para os "que se dedicam à psico-história, a relação entre a psicologia e a história revela-se inversa, no sentido de que é a psicologia que subordina a história" (p. 23). Para Augras (1985) “o termo psicologia da cultura talvez seja uma denominação mais adequada do que psicologia histórica" (p. 102). Massimi (2010) menciona a importância “do caráter essencial da historicidade da experiência humana, inclusive em sua dimensão psicológica” (p. 102). Essa diferença de interpretação justifica-se, primeiramente, pelo interesse de cada um: os textos de Penna (1981, 1982, 1987, 1988, 1991) priorizam relações entre história e psicologia; os textos de Augras $(1985,1988,1989,1997)$ demonstram foco na noção de cultura; já Massimi (2010) defende o termo como um dos métodos para pesquisa em história da psicologia.

Psicohistória, antropologia histórica, história das mentalidades e psicologia histórica surgiram em contextos específicos e tiveram diferentes percursos. A psicohistória surgiu nos Estados Unidos e em geral utiliza a psicanálise como base teórica; seu objetivo é compreender a função do inconsciente em eventos do passado e no desenvolvimento histórico; Beisel (1983), por exemplo, relata a existência da Associação psicohistórica internacional e da Associação francesa para o desenvolvimento da psicohistória, a oferta de cursos na França e nos Estados Unidos e refere como produção o livro Introdução à psicohistória, o The journal of psychohistory, e a Edições de psicohistória.

História das mentalidades e antropologia histórica são abordagens surgidas no ambiente dos historiadores franceses. Para Revel (1993), Ariès (1990) e Le Goff (1976) a noção de mentalidade foi reabilitada dos sentidos pejorativos, tal como primitivo, por Lucien Febvre e Marc Bloch. O termo, porém, não foi definido de modo rigoroso e representa um vasto e heterogêneo campo de interesse para os historiadores; seu objeto é o conteúdo cotidiano, automático e impessoal dos sujeitos históricos, aquilo que persiste na estrutura e nos sistemas de pensamento dos indivíduos. Assim, a noção de mentalidade e a "junção do individual e do coletivo, do longo tempo e do quotidiano, do inconsciente e do intencional" (Le Goff, 1976, p.71) propiciaram uma renovação no ofício do historiador.

Burguière (1990) e Revel (1993) consideram a antropologia histórica como mais um momento do fazer historiográfico. Ela não tem domínio próprio e seus temas pertencem a outros setores da história. É uma história dos hábitos e dos costumes que as instituições engendraram ao longo do tempo, história dos comportamentos "indefinidamente repetidos como coisa que não requer explicação” (Burguière, 1990, p. 59). Seu foco são as práticas sociais de menor importância, marginais, como as crenças populares, os ritos cotidianos, o folclore. $\mathrm{O}$ seu objetivo é "reconstituir o sistema lógico da sociedade [sabendo] que é sempre preciso contornar o que uma sociedade declara de si mesma para compreendê-la" (Burguière, 1990, p. 131-132).

Psicologia histórica, por sua vez, em parte também está vinculada aos Annales: além de menções em Berr, Febvre e Bloch, Robert Mandrou publicou dois livros (Mandrou, 1961, 1979). Charles Morazé e Ignace Meyerson ofereceram cursos sobre o tema à Escola de Altos Estudos em Ciências Sociais (Meyerson, 2000; Morazé, 1971-1972). Jean-Pierre Vernant, outro importante historiador francês que também usou o termo (Vernant, 1965), foi discípulo de Meyerson. Fora da França também há autores em psicologia histórica, a exemplo do psiquiatra holandês Jan Hendrik Van den Berg (1965) e do professor romeno Zevedei Barbu (1961). Exceto Meyerson e seu discípulo Vernant, os demais autores conceituam psicologia histórica a partir de sua própria perspectiva e em geral apenas nas obras referidas. O trabalho de Ignace Meyerson, por sua vez, foi sistemático e duradouro: a tese em que apresentou sua proposta foi defendida em 1947 (Meyerson, 1948). Entre 1951 e 1983 proferiu cursos na Escola Prática de Altos Estudos/Escola de Altos Estudos em Ciências Sociais; em 1953 fundou o Centro de Pesquisas em Psicologia Comparativa, onde organizou ciclos de conferência quinzenais e colóquios interdisciplinares. Meyerson também publicou diversos artigos ao longo de sua carreira (a este respeito ver Waeny, 2005). Para Meyerson (1948) o homem se expressa através das obras que tem produzido, e este traço constitutivo do homem torna possível seu estudo objetivo. Assim, as obras representam o homem de determinada época e local. Esta perspectiva histórica, por sua vez, coloca o problema do surgimento, mudança e desaparecimento de funções psicológicas no âmbito da própria historicidade do psiquismo, no âmbito da própria historicidade humana.

É possível identificar pelo menos dois motivos para a alternância entre os termos citados acima: um deles porque mentalidade, antropologia e psicologia já interessaram diferentes gerações dos Annales, de modo que a presença, por vezes simultânea, destes termos, talvez tenha dificultado as avaliações relativas a estas denominações. Um segundo motivo diz respeito à relação entre psicologia e história e a respectiva ênfase atribuída a cada um dos termos. A psicohistória, por exemplo, utiliza um referencial teórico da psicologia para abordar a história; mas se a ênfase recair na história, psicologia será aquilo que resulta do clima de uma determinada época, isto é, da mentalidade vigente para aquele período.

Aprofundar a análise da fronteira entre as denominações acima citadas e seus respectivos autores, no entanto, ultrapassa o objetivo deste texto, uma vez que o foco deste artigo é fornecer dados e fontes sobre a psicologia histórica disponíveis em acervos nacionais visando, assim, ampliar o conhecimento sobre ela, as denominações correlatas e alguns de seus protagonistas.

\section{A Psicologia Histórica no Brasil}

Pesquisa de Massimi (1990) fornece indícios de uma primeira menção à psicologia histórica no Brasil. Ela menciona que o manual Noções de philosophia: accommodadas ao systema de Krause e extrahidas das obras philosophicas de G. Tiberghien e Ahrens, assinado por Carlos Mariano Galvão Bueno, em 1877, apresenta duzentas e vinte páginas dedicadas 
à psicologia "classificada em psychologia experimental ou histórica e psychologia racional ou especulativa" (p. 32-33). Seria esta, portanto, a primeira menção até agora localizada no Brasil. Não se tem notícias de novas ocorrências do termo em autores brasileiros até seu reaparecimento, em 1978, desta vez pelas mãos de Eliezer Schneider, no capítulo Um ensaio de psicologia histórica. Controle social e sentimentos sociais (Schneider, 1978).

Todavia, apesar desta ausência de menções à psicologia histórica em autores nacionais durante quase um século, nesse mesmo período surgiram diversos títulos sobre o tema em catálogos de nossas bibliotecas universitárias, entre os quais Barbu (1961), Berr (1949), Gebhart (1896), Mandrou (1961, 1979), Van den Berg (1965), Vernant (1960, 1965). Os textos de autores nacionais, por sua vez, parecem ter acompanhado o ressurgimento do termo, em 1978 quando, além de Augras e Penna, surgiram textos tais como Almeida (1988), Cambauva, Silva e Ferreira (1997), Julien (2009), Neder e Cerqueira (2010).

Some-se a estes a produção sobre a psicologia histórica de Ignace Meyerson. São escritos do próprio Meyerson (1951, 1954, 1955, 1957, 1973, 1987); textos estrangeiros como Di Donato (1982), Fernandez-Zoila (1989), Leroy (1983, 1986), Malrieu (1978, 1990), Reuchlin (1965), Zac (1949); e textos nacionais como Augras (1985), Lima (2006), Massimi, Campos e Brozek (1996), Penna (1981, 1982, 1988), Waeny (2003, 2005); dissertações (Filippo, 1984; Waeny, 1998); monografias de conclusão de disciplina (Zonta, 1991), apresentações e/ou resumos em eventos científicos como Augras (1988), Doria (2007), Lima (2004), Waeny (1999, 2003).

Também se constata presença da psicologia histórica em cursos de universidades brasileiras. Ela já foi disciplina no extinto curso de pós-graduação do Instituto de Seleção e Orientação Profissional da Fundação Getúlio Vargas [ISOP/FGVRJ] e nos cursos de graduação de psicologia da Universidade do Estado do Rio de Janeiro [UERJ], da Fundação Mineira de Educação e Cultura [FUMEC] e da Universidade Federal de Juiz de Fora [UFJF] - desta já tendo sido, inclusive, objeto de edital público.

O documento do ISOP/FGV-RJ é o relatório para renovação no credenciamento do Doutorado em Psicologia Social e da Personalidade e Psicologia Cognitiva para o período 19851989 (Parecer n⿳o 414/68: processo $n^{-0}$ 23038.002930/85-58). O documento, em sete páginas, ao final apresenta duas listas relacionando professores e disciplinas oferecidas. À psicologia histórica foram atribuídas duas horas. Não há, porém, qualquer indicação do proponente dessa disciplina.

No caso da UERJ, psicologia histórica aparece como disciplina de graduação oferecida pelo Departamento de Psicologia Social e Institucional para o segundo semestre de 1999, com quatro créditos (UERJ, 1999). O conteúdo programático prevê três unidades: psicologia e história; história e desenvolvimento humano; perspectivas da psicologia histórica. Na bibliografia são relacionados historiadores franceses, Barbu e Van den Berg, e nenhuma menção a Meyerson. O documento não apresenta qualquer nome ou assinatura, mas consta um nome (Helmuth) nas propriedades do documento.

O documento da Fundação Mineira de Educação e Cultura
[FUMEC] é uma ementa para a disciplina Psicologia Social III. O conteúdo programático oferece, como primeira unidade, Por uma psicologia histórica, cujo objetivo é "empregar conceitos teóricos da psicologia social para analisar interações entre processos subjetivos e contexto social, histórico e cultural". $\mathrm{Na}$ ausência de dados sobre o autor e ano no texto original, foi possível apenas determinar um nome (Tania) e a data de criação do arquivo (16/9/2005). Embora este documento esteja indisponível para consulta online, há uma cópia dele no acervo gerado por esta pesquisa.

Os documentos da UFJF são dois concursos para seleção de professor substituto, em 2003 (Edital nº-4, de 27/01/2003) e 2005 (Edital $\mathrm{n}^{\mathrm{O}}$ 7, de 14/02/2005), e a contratação de 2003 (Extrato de contrato $\left.n^{\circ} 158 / 2003\right)$. Psicologia histórica, em ambos os casos, integra o conjunto de disciplinas objeto do edital. Para o período 2003-2004 o selecionado foi Marcelo Ribeiro Dantas. Mas parece não haver registros oficiais sobre o resultado do concurso de 2005. Ainda não se sabe como a disciplina foi inserida na grade deste curso e nem quanto tempo permaneceu como disciplina. Atualmente não mais integra o currículo do curso de psicologia dessa universidade.

Complementam esse panorama intercâmbios acadêmicos que também propiciaram a presença de protagonistas da psicologia histórica em instituições nacionais. Data de 1948 a tentativa de Ignace Meyerson para lecionar na Universidade de São Paulo (Charmasson, Démelier, Parot, \& Vermès, 1995, p. 63); e data de 1976 a chegada de Zevedei Barbu à Universidade de Brasília, cuja permanência estende-se até 1986 (Jornal da Tarde, 2004). Constata-se, finalmente, presença da psicologia histórica em associações científicas. Logo após a criação da Associação Nacional de Pesquisa e Pós-Graduação em Psicologia (ANPEPP), em 1983, foi organizado o I Simpósio Brasileiro de Pesquisa e Intercâmbio Científico. Na ocasião, a fim de retratar o estado da pós-graduação no país, pesquisadores apresentaram balanço dos últimos cinco anos sobre sua área de pesquisa. Foi este o objetivo de Monique Augras (1988) ao apresentar o texto Pesquisas em psicologia da cultura (1982-1987). À época interessada em pesquisas de campo que respeitassem a diversidade cultural brasileira, disse ela: "A primeira síntese dessa reflexão foi formalizada no [meu] artigo 'A psicologia da cultura'. Herdeira da psicologia histórica francesa [cita a tese de Meyerson]" (p. 97), passando então a mencionar as demais influências.

Outro simpósio da ANPEPP, o de 1996, foi orientado pela organização da Coletâneas ANPEPP, produção elaborada pelos grupos de pesquisa então existentes. No volume dedicado à história da psicologia (Campos, 1996) há um capítulo sobre métodos para historiografia da psicologia (Massimi, Campos, \& Brozek, 1996), no qual psicologia histórica figura como um dos recursos para a área. Esse texto ainda estabelece diferenças entre psicologia histórica, história das mentalidades e psicohistória (Massimi et al., 1996, 2008).

Os documentos disponíveis sobre a psicologia histórica permitem, então, começar a traçar sua história no Brasil. Este artigo, no entanto, privilegia a proposta de Ignace Meyerson. Para além de preferência pessoal, ele é o autor com a produção acadêmica mais sistemática, sendo que a maior parte de sua 
bibliografia está disponível em nossas bibliotecas universitárias e sua obra tem interessado diferentes gerações de pesquisadores brasileiros, a exemplo de Augras (1989, 1997), Penna (1988, 1991), Massimi (2010), Ferreira (2007), Waeny (1998 e 2005), Doria (2007) e Lima (2004, 2006).

\section{A Psicologia histórica de Ignace Meyerson no Brasil}

Devido ao pouco conhecimento de sua obra, uma breve nota biográfica antecede e esclarece os principais aspectos da vida de Ignace Meyerson. Pode-se dividir sua biografia em dois grandes períodos: de sua chegada a Paris às vésperas da II Guerra Mundial (1905-1939) e o período dedicado à psicologia histórica (19401983). Em Paris completou seus estudos, cumpriu residência na Salpêtrière sob orientação do psiquiatra francês Phillipe Chaslin, realizou pesquisas psico-fisiológicas no Instituto Marey junto com o médico e fisiologista francês Louis Lapicque; assumiu o secretariado da Sociedade francesa de Psicologia e do Journal de Psychologie Normale et Pathologique, tornouse assistente do psicólogo francês Henri Piéron no Laboratório de Psicofisiologia, traduziu Die Traumdeutung (Interpretação dos sonhos), de Sigmund Freud e iniciou uma longa pesquisa experimental sobre os chimpanzés, com o psicólogo francês Paul Guillaume. Entre suas atividades em psicologia histórica destacam-se: a fundação da Sociedade toulousiana de Psicologia Comparativa e organização de um colóquio ( $O$ trabalho $e$ as técnicas, 1941); a defesa da tese, Les fonctions psychologiques et les oeuvres (1948), quando formalizou sua proposta em psicologia histórica; o início de seus cursos sobre psicologia comparativa na Escola Prática de Altos Estudos/Escola de Altos Estudos em Ciências Sociais (1951); a fundação do Centro de Pesquisas em Psicologia Comparativa (1953), órgão promotor de ciclos de conferências quinzenais e de mais três colóquios (Problemas da cor, 1954; Problemas da pessoa, 1960; O signo e os sistemas de signos, 1962, tendo cumprido suas atividades regularmente até 1983 . Maiores detalhes sobre sua biografia podem ser obtidos em Waeny (2005), Pizarroso López (2007) e nos sites Espace Ignace Meyeson (http://bibliotheque.u-pec.fr/ espace-ignace-meyerson-homme-signes-culture-societe-240503. kjsp) e Site de l' exposition 2002 (http://aura.u-pec.fr/scd/ meyerson/i-meyerson-frame.htm).

$\mathrm{O}$ volume 521 AP 1 à 67. Archives d'Ignace Meyerson constitui o acervo do autor, atualmente depositado nos Archives Nationales. Nesse inventário (Charmasson et al., 1995), as pastas de número 45 a 62 contêm a correspondência; nelas estão relacionados os seguintes remetentes do Brasil: o médico e professor Afrânio Peixoto, a psicóloga e educadora Helena Antipoff, Consulado Geral da França em São Paulo e o filósofo João Cruz Costa (as traduções a seguir são do autor deste artigo).

A carta de Afrânio Peixoto é de 01/11/1919. Trata-se de alguma resposta a Meyerson, então secretário do Journal de Psychologie Normale et Pathologique. Disse Afrânio: "Em resposta a sua carta de 26/07/1919, também assinada pelos professores Pierre Janet e George Dumas, asseguro estar honrado com a proposta e à sua completa disposição". Segundo Pizarroso López (2007), Janet e Dumas pretendiam incluir autores de diversas nacionalidades, e fazer desse periódico um intermediário entre filósofos, psicólogos, juristas, educadores, sociólogos e médicos. Esta carta, portanto, provavelmente responde a convite para tal empreitada.

O cartão postal de Helena Antipoff data de 5/4/1927. Ele foi endereçado a Madame Reynier, porém não há registros de contato entre ela e Meyerson, e o texto do cartão também não o menciona. Não se sabe porque tal correspondência pertence ao acervo Meyerson.

A correspondência com o Consulado Geral da França em São Paulo versa sobre vaga pleiteada por Meyerson na USP. Disse Ignace em telegrama de 15/11/1947:

Da parte de Gurvitch solicito responder telegraficamente [com] extrema urgência [se o] cônsul francês em São Paulo pode assegurar ensino de psicologia experimental no semestre maiooutubro de 1948 se possível [19]49 e [19]50 na Faculdade de Letras de São Paulo... autoridades francesas de acordo.

A resposta, em 26/11/1947, foi a seguinte:

Recebi esta manhã sua carta... comuniquei o teor ao Diretor da Faculdade de Filosofia, Ciências e Letras da Universidade de São Paulo. Ele me disse interessar-se pelo ensino de Psicologia aplicada. A nítida preferência pelo ensino de psicologia experimental pura o põe fora de circuito. Eu me desculpo porque nosso amigo comum, Georges Gurvitch, falou calorosamente de você.

Qual o interesse de Meyerson em passar uma temporada no Brasil e por que a urgência na resposta? De Toulouse, onde então lecionava, ele desejava retornar à capital francesa. A chance surgiu quando de um concurso para a almejada Universidade de Paris, vaga para a qual também se candidataram o psiquiatra e psicanalista francês Daniel Lagache e o médico e psicólogo francês André Ombredane. Ombredane e Meyerson rapidamente redigiram suas teses a fim de concorrer à vaga, mas o resultado, em junho de 1947, elegeu Lagache (Di Donato, 1995; Pizarroso López, 2007).

João Cruz Costa remeteu três cartas a Meyerson. O inventário deste, porém, não acusa nenhuma resposta ao filósofo uspiano. Escreveu ele a Meyerson, em 27/4/1952:

Terminei a leitura de seu livro: "As funções psicológicas e as obras". Seu livro esclarece uma série de questões que não estavam nítidas para mim até agora. Apresento, portanto, minhas felicitações. Desculpe não nos despedirmos após minha partida de Toulouse, onde nos encontramos ano passado [1951]. Minha passagem por Paris foi curta e rápida. Em todo caso, espero retornar logo para expressar, à viva voz, minha admiração. Queira desculpar, não tive tempo de dizer adeus em Paris. Mas venho também dizer [ilegível] seu trabalho me interessa.

Apesar da declarada admiração e interesse, ainda não foram encontrados registros de como Cruz Costa teve acesso à tese Les fonctions... (Meyerson, 1948), sobre como conheceu Meyerson. Sabe-se que Cruz Costa, ex-professor de psicologia no curso de filosofia da USP, em 1923 passou uma temporada em Paris, ocasião em que também frequentou as aulas do psiquiatra francês Pierre Janet e do médico francês George Dumas (Costa, 1975, p.87-88). Nessa época Meyerson mantinha estreita relação com Janet e Dumas - inclusive, foi a convite deste último que Meyerson, em 1920, assumiu o cargo de secretário da Sociedade 
francesa de Psicologia e do JPNP.

Necessário é lembrar que o próprio Cruz Costa identificou uma guinada disciplinar em fins de 1940. Seu interesse pela história, até então um hobby, "transformou-se em quase angustiosa e justificada preocupação. Foi a essa altura que comecei a tentar imaginar as curiosas vicissitudes das ideias no Brasil” (Costa, 1968, p.7). Nessa época ele já conhecia a psicologia histórica, fosse esta à la Meyerson, Febvre ou Charles Morazé, pois mencionou ambos, Febvre e Morazé, em seus textos (Costa, 1968). Vale lembrar que Morazé, embora menos conhecido, também era um historiador vinculado aos Annales e detinha a cadeira psicologia histórica na Escola Prática de Altos Estudos/Escola de Altos Estudos em Ciências Sociais.

\section{Considerações finais}

Para analisar a presença da psicologia histórica no Brasil é necessário considerar os diversos contextos nos quais foi referida. Os exemplos abaixo ilustram a diversidade de contextos relativos à sua história.

É possível que o interesse de Meyerson no Brasil, por exemplo, tenha surgido pelas notícias daqueles que por aqui passaram? O concorrente Ombredane (Penna, 2001), por exemplo, lecionou na então capital federal; o amigo Henri Piéron, que apoiou sua candidatura à Sorbonne (Pizarroso López, 2007, p. 246-269), proferiu cursos de psicometria em São Paulo; Georges Dumas, outro amigo de Meyerson, era pessoa influente na seleção dos professores que viriam ao Brasil (Petitjean, 1996); o sociólogo francês Georges Gurvitch, que o indicou à USP, integrou as famosas missões francesas para esta universidade.

Outro exemplo, o contato entre Cruz Costa e Meyerson. Neste caso, antes é preciso esclarecer que o pensamento de Cruz Costa foi eclipsado por diversos motivos: o ex-aluno Bento Prado Júnior o criticou pelo excesso de historicismo e psicologismo de suas análises (Prado Junior, 1986). Cortês (2005) alega o interesse em investigar a saga do pensamento brasileiro a partir da própria história nacional quando ainda não se fazia isso no país. Para Bontempi Junior (2009) teria sido o contato com o pensamento e obra de Marx antes de sua repercussão nas universidades brasileiras, e também por transitar entre a filosofia e a história. Bontempi Junior (2009) diz também que a admiração do filósofo brasileiro pelos historiadores dos Annales motivou rejeição por parte dos departamentos de história e de filosofia da USP. Tais dados levam a considerar que o pensamento de Cruz Costa, avançado para sua época, tornou-se vítima da própria originalidade. De modo que o contato entre ele e Meyerson deve considerar este aspecto.

Outra fonte para análise são os documentos institucionais, mas por terem teor muito distintos entre si, só o contato direto com essas fontes permitirá conclusões mais substanciais.

A diversidade de conteúdo parece também caracterizar os autores que mencionam psicologia histórica: Penna, por exemplo, demonstra interesse pelas relações entre psicologia e história (Penna, 1982, 1987, 1988); Augras (1989, 1997) prioriza a noção de cultura; Galvão Bueno a inclui em uma das divisões da psicologia; Schneider (1978) a vincula à psicologia social; Cruz Costa parece não ter deixado traços diretos desta relação; e Bento Prado Junior traduziu livro com um capítulo específico sobre a psicologia histórica de Ignace Meyerson (Reuchlin, 1957), mas até agora não foram localizados registros ou menções suas a respeito da psicologia histórica ou sobre Ignace Meyerson.

Por outro lado, autores que mencionam psicologia histórica o fazem via Vernant ou parafraseando um pequeno trecho de Meyerson, a exemplo da primeira dissertação defendida no país sobre a psicologia histórica (Filippo, 1984). O texto dedicou apenas uma página a Meyerson e, embora inclua a tese de 1948 na bibliografia, não faz citação direta e não menciona ou analisa mais detidamente a proposta meyersoniana. Desta banca participaram Antonio Gomes Penna (orientador), Eva Nick e Eliezer Schneider.

Há uma justificativa aceitável para tantas referências indiretas a Meyerson. A maior parte de seus artigos foram publicados no Journal de Psychologie Normale et Pathologique, coleção nem sempre disponível ou completa nos acervos consultados (a biblioteca da PUC-São Paulo, por exemplo, não tem a coleção completa; a biblioteca do Instituto de Psicologia da USP tem a maioria dos números, mas os volumes anteriores a 1950 foram transferidos para uma sala de obras raras); uma primeira coletânea, Écrits 1920-1940. Pour une psychologie historique, surgiu somente em 1987 (Meyerson, 1987); e a tese defendida em 1947 (Meyerson, 1948), esgotada, só foi reimpressa em 1995. Dos livros de Meyerson que chegaram a nossas bibliotecas conhece-se apenas a procedência da coletânea (Meyerson, 1987): ele pertence à Biblioteca do Instituto de Psicologia da USP, adquirido pelo Departamento de Psicologia Social e do Trabalho, a pedido do professor João Augusto Frayze-Pereira.

Devido a esta recorrência da psicologia histórica em vários âmbitos e ao longo do tempo na história acadêmica nacional, torna-se possível mensurar sua presença no país. Traçar essa história, porém, solicita ampla coleta de informações e criteriosa análise de fontes que sejam compatíveis à diversa e longa duração de sua presença no Brasil. Os dados até agora apresentados, mesmo que significativos, são traços, indícios, para uma história da psicologia histórica no Brasil.

A presença da psicologia histórica no Brasil está em consonância com seu percurso no âmbito de sua história mais geral. Segundo Waeny (2013), embora costume-se atribuir a Henri Berr o pioneirismo no uso do termo, em 1899, a primeira menção data de 1833, também na França; a esta seguiu-se a publicação de títulos entre 1896-1909 e depois entre 19471965. No caso do Brasil, o primeiro autor que usou o termo foi Galvão Bueno, em 1877, justamente no período que antecedeu o surgimento de títulos. Já o ressurgimento do termo (Schneider, 1978), embora posterior ao período 1947-1965, aborda o aspecto cultural dos eventos, e por este motivo pode-se incluí-lo na segunda geração de títulos em psicologia histórica.

A história da psicologia histórica também pode contribuir para esclarecer alguns dos julgamentos a respeito do termo. A antecedência no uso do termo desde 1833 pode mostrar, por exemplo, que a introdução da psicologia histórica no ambiente dos Annales foi fruto de uma tendência do período e não somente porque interessou Berr, Febvre ou Bloch; também é possível expandir o sentido do trecho de Berr sobre o surgimento das 
diversas psicologias, mencionada anteriormente, pois talvez ele tenha sido o relato sobre a importância que a psicologia estava adquirindo como fator explicativo para os eventos históricos.

A perspectiva de uma história da psicologia histórica também pode contribuir para esclarecer alguns dos motivos para a alternância entre os termos citados anteriormente. Segundo Waeny (2013) o denominador comum em torno do qual se agrupam os títulos em psicologia histórica, entre 1947-1965, é a crítica ao caráter ideológico das noções de Cultura e Civilização. Esta crítica resultou na renovação do conceito de cultura, que passou a ser visto como "produção e compartilhamento de processos simbólicos” (Waeny, 2013, p.126). É neste sentido que se pode compreender, por exemplo, a retomada do termo mentalidades e a proposição de uma antropologia histórica no ambiente dos Annales, o surgimento de nova rodada de títulos em psicologia histórica e a elaboração de uma psicohistória, pois estas abordagens partem da mediação cultural que permeia os fenômenos e eventos históricos, sociais e individuais.

Por fim, resta explicitar a opção pela proposta de Meyerson diante das demais abordagens aqui referidas. O principal motivo é a precisão relativa à própria possibilidade de uma psicologia histórica. Escreve ele na ementa à Escola Prática de Altos Estudos, em 1969/1970: "Significação psicológica do pensamento histórico: ele representa uma mutação mental, uma invenção nos domínios da memória e do tempo. Aparição das diversas histórias; a história das funções psicológicas do homem se enquadra nesta série" (citado por Waeny, 2005, p. 135). Outro motivo é como aborda os temas. Meyerson parece sempre considerar a longa duração e, nela, os cortes, as rupturas, as nuances e consequências daí decorrentes. Por fim, outro motivo é a abrangência dentro de um determinado tema. Nos cursos sobre o surgimento e constituição da subjetividade, por exemplo, ele trata dos princípios de uma ciência do individual, do surgimento da noção de eu, analisa autores que tomaram o eu como tema de reflexão, analisa a expressão da pessoa nos escritos literários, biográficos ou autobiográficos; nos cursos abordando as artes plásticas, outro exemplo, ele analisa o quadro como objeto físico, técnico, artístico, estético, social; analisa aspectos técnicos como o corante e o diluente, o verniz, a transparência e a luminosidade, e aspectos históricos como a introdução do óleo e a importância do material e da técnica sobre a expressão artística (sobre os cursos, ver Waeny, 2005). Estes exemplos servem para demonstrar o esforço de Ignace Meyerson para apreender, do modo mais rigoroso possível, o fazer humano em toda sua historicidade e em todas as suas facetas e nuances. Estes são alguns dos motivos para que, na história da psicologia histórica e no âmbito das demais abordagens históricas e culturais, o destaque seja atribuído à proposta de Ignace Meyerson.

\section{Referências}

Almeida, A. R. (1988). Quem é o brasileiro? In Associação Brasileira de Psicologia Social (Org.), III Encontro Mineiro de Psicologia Social. Anais (pp. 65-84). Belo Horizonte: Abrapso.

Ariès, P. (1990). A história das mentalidades. In J. Le Goff (Org.) (1990), A história nova (pp. 153-175). São Paulo: Martins Fontes.

Augras, M. R. A. (1985). A psicologia da cultura. Psicologia: Teoria e pesquisa,
1(2), 99-109

Augras, M. R. A. (1988, março). Pesquisas em psicologia da cultura (19821987). Comunicação apresentada no $1^{\circ}$ Simpósio brasileiro de pesquisa e intercâmbio científico, Caruaru. Resumo recuperado de http://www.infocien. org/Interface/Simpos/An01T14.pdf

Augras, M. R. A. (1989, agosto/setembro). Psicologia da cultura e psicologia histórica: novas perspectivas. Comunicação apresentada no V Encontro Nacional de Psicólogos e Profissionais de Ciências Sociais, Rio de Janeiro.

Augras, M. R. A. (1997). De la psicologia historica la psicologia de la cultura. Revista del Museo Mitre, 10, 25-39.

Barbu, Z. (1961). Problems of historical psychology. Londres: Routledge \& Kegan Paul.

Beisel, D. R. (1983). Editor's foreword. The journal of psychohistory, 11(1), 3-8.

Berr, H. (1949). Peut-on expliquer l'Allemagne? Psychanalyse ou psychologie historique. Revue de Synthèse, 65, 9-66.

Bontempi Junior, B. (2009). Rivalidade, parricídio intelectual e invasão de fronteiras na trajetória de Cruz Costa. Anos 90, 16(29), 155-181.

Burguière, A. (1990). Antropologia histórica. In J. Le Goff (Org.). (1990), A história nova (pp. 125-152). São Paulo: Martins Fontes.

Burke, P. (1990). A escola dos Annales 1929-1989. A Revolução Francesa do historiografia. São Paulo: UNESP.

Cambauva, L. G.; Silva, L. C., \& Ferreira, W. (1997). Da história da psicologia à psicologia histórica. Psicologia em Estudo, 2(2), 113-124.

Campos, R. H. F. (Org.) (1996). História da Psicologia. Rio de Janeiro: ANPEPP.

Chalus, P. (1961). Avant-Propos. In R. Mandrou (Org.), Introduction à la France moderne: essai de psychologie historique (pp. 9-22). Paris: Albin Michel.

Charmasson, T.; Démelier, D.; Parot, F., \& Vermès, G. (1995). 521 AP 1 à 67 : Archives d'Ignace Meyerson. Paris: Archives Nationales.

Côrtes, N. (2005). História das idéias em Nelson Werneck Sodré e João Cruz Costa: Uma saga da consciência nacional. Caderno CRH, 18(44), 229-235. Recuperado de http://www.cadernocrh.ufba.br/viewarticle.php?id=50

Costa, J. C. (1968). Prefácio. In C.G. Mota (Org.), 1974. Brasil em perspectiva. (pp. 7-9). São Paulo: Difel.

Costa, J. C. (1975). Sobre o trabalho técnico. Trans/form/ação: Revista de filosofia, 2, 87-94.

Di Donato, R. (1982). Invitto alla lettura dell'opera di Ignace Meyerson: Psicologia storica e studio del mondo antico. Annali della Scuola Superiore di Pisa, $12(2), 602-644$.

Di Donato, R. (1995). Postface. In I. Meyerson (Org.), Les fonctions psychologiques et les oeuvres (pp. 223-272). Paris: Albin Michel.

Doria, N. G. (2007). Lições da história da psicologia sobre as relações entre psicologia e história: Vigotski e Meyerson e as transformações do psiquismo. In VI Encontro Interinstitucional de Pesquisadores em História da Psicologia, Resumos (p. 27). Maceió: Autor.

Dosse, F. (1994). A história em migalhas: Dos Annales à nova história. São Paulo: Ensaio.

Edital nº̂4, de 27/01/2003: Seleção de professor substituto. (2003, 29 de janeiro). Diário Oficial da União. Recuperado de http://www.in.gov.br/imprensa/ visualiza/index.jsp?jornal $=3$ \&pagina $=13 \&$ data $=29 / 01 / 2003$

Edital $\mathrm{n}^{\mathrm{0}} 7$, de 14/02/2005: Seleção de professor substituto. (2005, 22 de fevereiro). Diário Oficial da União. Recuperado de http://www.in.gov.br/imprensa/ visualiza/index.jsp?jornal $=3 \&$ pagina $=46 \&$ data $=22 / 02 / 2005$

Extrato de contrato $\mathrm{n}^{\mathrm{o}}$ 158/2003. (2003, 29 de abril). Diário Oficial da União. Recuperado de http://www.in.gov.br/imprensa/visualiza/index.jsp?jornal=3 \&pagina $=21 \&$ data $=29 / 04 / 2003$

Fernandez-Zoila, A. (1989). Psychologie historique et psychopathologie: 1) Fondements. A propos d'Écrits 1920-1983. L'Evolution psychiatrique, 54(1), 167-182

Ferreira, A. A. L. (2007). A diferença que nos une: O múltiplo surgimento da psicologia. Revista do Departamento de Psicologia - UFF, 19(2), 477-500.

Filippo, A. C. (1984). A diferença entre a história da psicologia e a psicologia histórica (Dissertação de Mestrado não publicada). Fundação Getulio Vargas, 
Rio de Janeiro.

Galvão Bueno, C. M. (1877). Noções de philosophia: Accommodadas ao systema de Krause e extrahidas das obras philosophicas de G. Tiberghien e Ahrens. São Paulo: Typ. de Jorge Seckler.

Gebhart, E. (1896). Moines et papes, essais de psychologie historique: Un moine de l'an 1000: Sainte Catherine de Sienne: les Borgia: le dernier paperoi. Paris: Hachette.

Jornal da Tarde (2004, 24 de maio). Zevedei Barbu e o Brasil. Recuperado de http://www.asymetria.org/modules.php?name=News\&file $=$ article\&sid $=542$

Julien, A. (2009). A Psicologia Histórica de Jean-Pierre Vernant. Cadernos UFS - Filosofia, 5, 17-23.

Le Goff, J. (1976). Mentalidades, uma história ambígua. In J. Le Goff \& P. Nora (Orgs.) (1976), História: Novos objetos (pp. 68-83). Rio de Janeiro: Francisco Alves.

Leroy, Y. (1983). Ignace Meyerson. Journal de Psychologie Normale et Pathologique, 4, 358-359.

Leroy, Y. (1986). Éléments pour une biographie d'Ignace Meyerson: Le Centre de Recherches de Psychologie Comparative: trente ans de psychologie historique. Journal de Psychologie Normale et Pathologique, 1/2, 93-101.

Lima, R. S. (2004, outubro). A Psicologia histórica de Ignace Meyerson. Comunicação apresentada no VI Encontro Clio-Psyché, Rio de Janeiro. Resumo recuperado de http://www.cliopsyche.uerj.br/encontros/6resumos/ comunic $2 . \mathrm{htm}$

Lima, R. S. (2006). A Psicologia em Ignace Meyerson. In C. D. C. Tourinho, M. S. Ferreira, N. F. Ribeiro da Silva \& R. S. Lima (Orgs.), Ensaios sobre o pensamento contemporâneo: Bergson, Benjamin, Foucault e Meyerson (pp. 81-92). Niterói: Proclama.

Malrieu, P. (1978). Psychologies genétiques et psychologie historique. Journal de Psychologie Normale et Pathologique, 3, 261-277.

Malrieu, P. (1990). Écrits, d'Ignace Meyerson: Pour une psychologie historique. Raison presente, 95, 101-106.

Mandrou, R. (1961). Introduction à la France moderne (1500-1640): Essai de psychologie historique. Paris: Albin Michel.

Mandrou, R. (1979). Magistrados e feiticeiros na França do século XVII. Uma análise de psicologia histórica. São Paulo: Perspectiva.

Massimi, M. (1990). História da psicologia brasileira. São Paulo: EPU.

Massimi, M., Campos R. H. F., \& Brozek, J. (1996). Historiografia da psicologia: Métodos. In R. H. F. Campos (Org.), História da psicologia (pp. 29-56). São Paulo: Educ.

Massimi, M., Campos R. H. F., \& Brozek, J. (2008). Historiografia da psicologia: Métodos. In: R. H. F. Campos (Org.), História da psicologia (pp. 21-48). Recuperado de http://www.bvce.org/DownloadArquivo. asp?Arquivo=CAMPOS_Historia_da_psicologia_ANPEPP. pdf_28_10_2008_13_50_50.pdf.

Massimi, M. (2010). Métodos de investigação em história da psicologia. Psicologia em pesquisa, 4(2), 100-108.

Meyerson, I. (1948). Les fonctions psychologiques et les oeuvres. Paris: Vrin.

Meyerson, I. (1951). L'intelligence plénière. In Centre international de synthèse. (Org.), Valeur philosophique de la psychologie (pp. 129-157). Paris: PUF.

Meyerson, I. (1954). La psychologie du XXe siècle. Paris: PUF.

Meyerson, I. (1955). Le travail les métiers l'emploi. Paris: PUF.

Meyerson, I. (1957). Problèmes de couleur. Paris: S.E.V.P.E.N.

Meyerson, I. (1973). Problèmes de la personne. Paris: Mouton.

Meyerson, I. (1987). Écrits 1920-1983: Pour une psychologie historique. Paris: PUF.

Meyerson, I. (2000). Existe-t-il une nature humaine? Psychologie historique, objective, comparative. Paris: Sanofi-Synthélabo.

Morazé, C. (1971-1972). Psychologie historique. Annuaire. Comptes rendus 1971-1972 (pp. 152-155). Paris: École Pratique des Hautes Études.

Neder, G., \& Cerqueira, G. S. (2010). Sentir e julgar: A psicologia histórica das criminalizações e punições. Revista Epos - Genealogias Subjetivações e Violências, $I$ (2). Recuperado de http://revistaepos.org/?p=129\#titulo
Parecer $n^{0}$ 414/68: processo $n^{0}$ 23038.002930/85-58. (1986, 30 de junho). Recuperado de http://www.dominiopublico.gov.br/download/texto/ cd008567.pdf

Penna, A. G. (1981). História das ideias psicológicas. Rio de Janeiro: Zahar.

Penna, A. G. (1982). Psicologia e história. Arquivos brasileiros de psicologia, 34(3), 89-95.

Penna, A. G. (1987). Psicologia e história. In A. G. Penna (Org.), História e psicologia (pp. 17-26). Rio de Janeiro: Vértice.

Penna, A. G. (1988). As funções psicológicas e o tempo. Arquivos brasileiros de Psicologia, 40(4), 17-24.

Penna, A. G. (1991). Psicologia e história: A psicologia histórica. In A.G. Penna, História das idéias psicológicas (pp. 41-48). Rio de Janeiro: Imago.

Penna, A. G. (2001). André Ombredane. In R. H. F. Campos (Org.), Dicionário biográfico da psicologia no Brasil: Pioneiros (pp. 266-267). Rio de Janeiro: Imago.

Petitjean, P. (1996). As missões universitárias francesas na criação da Universidade de São Paulo (1934-1940). In A. I. Hamburger, M. A. Dantes, M. Paty \& P. Petitjean (Orgs.), As ciências nas relações Brasil-França (1850-1950) (pp. 259-330). São Paulo: Edusp/Fapesp.

Pizarroso López, N. (2007). La psicología histórica de Ignace Meyerson (Tese de Doutorado). Universidad Complutense de Madri/Université Paris Descartes, Madri/Paris. Recuperado de: http://eprints.ucm.es/9158/1/T30963.pdf

Prado Junior, B. (1986). Cruz Costa e a história das idéias no Brasil. In R. Moraes, R. Antunes \& V. B. Ferrante (Orgs.), Inteligência brasileira (pp. 101-124). São Paulo: Brasiliense.

Reuchlin, M. (1957). Histoire de la psychologie. Paris: PUF.

Reuchlin, M. (1965). A psicologia histórica de Ignace Meyerson. In M. Reuchlin (Org.), História da psicologia (B. Prado Junior, Trad.) (pp. 124-125). São Paulo: Difel.

Revel, J. (1993). Mentalidades. In A. Burguière (Org.). (1993), Dicionário de ciências históricas (pp. 528-535). Rio de Janeiro: Imago.

Schneider, E. (1978). Um ensaio de psicologia histórica: Controle social e sentimentos sociais. In E. Schneider (Org.), Psicologia social: Cultura: Histórica: Política (pp.134-179). Rio de Janeiro: Guanabara.

UERJ. (1999). Programa de disciplina. Recuperado de http://www.psicologia. uerj.br/ementario/ementas/eletivas/PH.pdf

Van Den Berg, J. H. (1965). Metablética: Psicologia histórica. São Paulo: Mestre Jou.

Vernant, J. P. (1960). Sur les recherches de psychologie comparative historique. Journal de Psychologie Normale et Pathologique, 4, 45-51.

Vernant, J. P. (1965). Mythe et penseé chez les grecs: Études de psychologie historique. Paris: Maspero.

Waeny, M. F. C. (1998). A psicologia histórica de Ignace Meyerson (Dissertação de Mestrado não publicada). Pontifícia Universidade Católica de São Paulo, São Paulo.

Waeny, M. F. C. (1999, maio). Quadro sintético das relações acadêmicas de Ignace Meyerson. Trabalho apresentado no I Congresso Norte-Nordeste de Psicologia, Salvador.

Waeny, M. F. C. (2003). A psicologia histórica de Ignace Meyerson. Trabalho apresentado no II Encontro Interinstitucional de Pesquisadores em História da Psicologia, Belo Horizonte.

Waeny, M. F. C. (2005). Bibliografia de Ignace Meyerson. Memorandum: Memória e história em psicologia, 9, 132-140. Recuperado de http://www. fafich.ufmg.br/ memorandum/a09/waeny03.htm

Waeny, M. F. C. (2013). Por uma história da psicologia histórica. Memorandum, 24, 122-132. Recuperado de www.fafich.ufmg.br/memorandum/a24/ waeny04.

Zac, S. (1949). La théorie des fonctions psychologiques d' I. Meyerson. Revue de synthèse, 65, 92-97.

Zonta, C. (1991). A psicologia histórica: Caminhos, limites e possibilidades no contexto da ciência (Manuscrito não publicado). Pontifícia Universidade Católica de São Paulo, São Paulo. 
Maria Fernanda Costa Waeny, Doutora e Pós-Doutora em História da Psicologia pelo Programa de Estudos Pós-Graduados em Psicologia Social da PUCSP, membro do Núcleo de Estudos em História da Psicologia da PUCSP (NEHPsi). Endereço para correspondência: Rua Aparandé, 146 Ap.23A, CEP 05054-070, Vila Ipojuca, São Paulo-SP. Telefone (11) 99469-6657. E-mail: fernandawaeny@gmail.com 